\title{
Radiofrequency ablation of pulmonary malignant tumors in nonsurgical candidates
}

\author{
Luis J. Herrera, MDa \\ Hiran C. Fernando, $\mathrm{MD}^{\mathrm{a}}$ \\ Yaron Perry, MD \\ William E. Gooding, $\mathrm{MS}^{\mathrm{b}}$ \\ Percival 0. Buenaventura, $\mathrm{MD}^{\mathrm{a}}$ \\ Neil A. Christie, MD \\ James D. Luketich, MDa
}

See related editorial on page 787.
From the Department of Surgery, Division of Thoracic and Foregut Surgery, ${ }^{\mathrm{a}}$ and the Department of Biostatistics, Pittsburgh Cancer Institute, ${ }^{\text {b }}$ University of Pittsburgh, Pittsburgh, Pa.

Received for publication July 9, 2002; revisions requested July 25, 2002; revisions received Sept 23, 2002; accepted for publication Sept 24, 2002.

Address for reprints: James D. Luketich, MD, Associate Professor of Surgery, Chief, Division of Thoracic and Foregut Surgery, Suite C-800, Presbyterian University Hospital, 200 Lothrop St, Pittsburgh, PA 15213 (E-mail: luketichjd@msx.upmc.edu).

J Thorac Cardiovasc Surg 2003;125:929-37

Copyright $(\odot 2003$ by The American Association for Thoracic Surgery

$0022-5223 / 2003 \$ 30.00+0$

doi: $10.1067 / \mathrm{mtc} .2003 .18$
Objective: Radiofrequency ablation applies thermal energy with a catheter delivery system, resulting in coagulation necrosis. Radiofrequency ablation is frequently used for hepatic malignant tumors, but few reports exist regarding its use for lung tumors. We report our experience with radiofrequency ablation for the treatment of pulmonary malignant tumors.

Methods: We evaluated the results of lung radiofrequency ablation for patients not considered surgical candidates. Indications for radiofrequency ablation were pulmonary malignant tumors in patients with medical comorbidities, pulmonary compromise, or refusal of surgery.

Results: Thirty-three lung tumors in 18 patients (12 male, 6 female) were treated with radiofrequency ablation. Tumors included metastatic carcinoma $(\mathrm{n}=8)$, sarcoma $(\mathrm{n}=5)$, and lung cancer $(\mathrm{n}=5)$. Mean age was 60 years (range 27-95 years). Thoracic surgeons performed radiofrequency ablation by minithoracotomy $(\mathrm{n}=5)$ or computed tomography-guided percutaneous methods $(\mathrm{n}=13)$ with patients under general anesthesia in the operating room. Mean length of stay was 3 days (range 1-7 days). Complications included procedure-related pneumothorax in 7 of 13 percutaneous procedures $(53.8 \%)$, delayed pneumothorax (1/18), pneumonitis/pneumonia (4/18), small pleural effusion (9/18) and transient renal failure $(1 / 18)$. One death occurred as a result of hemoptysis 19 days after radiofrequency ablation of a central nodule. This patient had also received recent brachytherapy. After a mean follow-up of 6 months (range 1-14 months), radiofrequency ablation had achieved a radiographically determined response in 8 of 12 patients with treated tumors smaller than $5 \mathrm{~cm}(66.6 \%)$. Death with progressive metastatic disease occurred in 7 of 18 patients (38\%) during follow-up.

Conclusion: This pilot study demonstrates the feasibility of radiofrequency ablation for small peripheral lung tumors. Larger tumors responded poorly. Additional trials are needed to determine safety and efficacy.

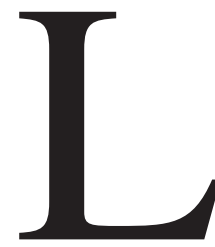

ung cancer is currently the most common cause of cancer-related death in the United States and represents the second most common malignancy, with 171,400 new cases in the year 1999.1,2 Surgical resection remains the mainstay of therapy for early stage non-small cell lung cancer (NSCLC) and is also beneficial for selected patients with limited pulmonary metastases from extrathoracic primary tumors. ${ }^{3}$

There are patients with malignant pulmonary disease who would potentially benefit from surgical therapy, however, but face a prohibitive surgical risk because 


\section{TABLE 1. Characteristics of patients treated with RFA}

\begin{tabular}{lc}
\hline Age (y, mean and range) & $60(27-95)$ \\
Sex (No.) & $12(66 \%)$ \\
Male & $6(33 \%)$ \\
$\quad$ Female & $15(83.3 \%)$ \\
Previous therapy (No.) & $9(50 \%)$ \\
$\quad$ Chemotherapy & $1(5.6 \%)$ \\
Radiotherapy & $1(5.6 \%)$ \\
Brachytherapy & $9(50 \%)$ \\
$\quad$ Photodynamic therapy & \\
Resection & $12(66.6 \%)$ \\
Main reason for no resection & \\
$\quad$ Inadequate predicted postoperative pulmonary & $3(16.7 \%)$ \\
$\quad$ reserve & $2(11.1 \%)$ \\
$\quad$ Refusal of surgery & \\
Severe chronic obstructive pulmonary disease & $1(5.6 \%)$ \\
$\quad$ or cardiac risk & \\
$\quad$ Advance age (95 y) & $5(27.8 \%)$ \\
Tumor type & $13(72.2 \%)$ \\
$\quad$ NSCLC & \\
$\quad$ Metastatic & $5(27.8 \%)$ \\
RFA approach & $13(72.2 \%)$ \\
$\quad$ Minithoracotomy & $3.4(1-12)$ \\
$\quad$ CT guided & \\
Hospital stay (d, mean and range) & \\
$\quad$ &
\end{tabular}

of poor pulmonary function or severe medical comorbidities. Treatment alternatives to surgery include chemotherapy and radiation, and in general long-term survivals are lower than those achieved with complete resection. As an alternative, these patients could potentially benefit from minimally invasive ablative therapies that preserve unaffected lung parenchyma. Radiofrequency ablation (RFA) has been used extensively in the treatment of liver tumors in patients who are not candidates for resection. ${ }^{4,5}$ RFA is a thermal energy delivery system that applies an alternating current supplied by a radiofrequency energy generator delivered though a needle electrode. After introduction of the needle electrode into the tissue, multiple tines or hooks are deployed within the tumor. This allows for maximal distribution of energy and an increase in the size of the thermal lesion. The alternating current generates ionic agitation, creating a temperature as great as $100^{\circ} \mathrm{C}$ and resulting in coagulative necrosis and tissue destruction in the vicinity of the probe.

Since the widespread application of RFA for the ablation of unresectable liver tumors, this technique has been considered as an alternate therapy for the destruction of other solid tumors. Animal studies investigating the histologic effects of RFA on pulmonary parenchyma revealed that tumors can be ablated effectively, with minimal damage to surrounding unaffected lung. ${ }^{6,7}$ The clinical experience of RFA in the treatment of pulmonary malignancies is limited, but unpublished large series from the People's Republic of China and pilot studies in the United States suggest that it can be applied successfully with minimal complications. ${ }^{8-11}$
The objective of this study was to evaluate the effects of RFA of lung tumors of patients ineligible for standard surgical resection. Our main goal was to determine, in preparation for a controlled prospective trial, the safety and feasibility of this approach for treating malignant pulmonary disease in patients who are not candidates for resection by evaluating of early outcomes and radiographically determined response after RFA. Here we present our experience with RFA for the treatment of malignant pulmonary disease in patients not considered candidates for resection.

\section{Methods}

\section{Patient Selection}

We performed a retrospective review in the division of thoracic surgery of all 18 patients with lung tumors treated with RFA at the University Of Pittsburgh Medical Center from September 2000 to March 2002 with approval from our institutional review board. We selected patients who had failure of previous nonoperative therapies or who, despite the presence of resectable disease, were considered not to be candidates for complete resection because of poor physiologic reserve or patient refusal. This group included patients with both primary and secondary pulmonary tumors. All patients had disease localized to the lungs, and treatment was performed with the intent of cure or for local tumor control. In light of the high risk associated with pulmonary resection in this group of patients, it was considered that a minimally invasive procedure could be a reasonable alternative because of the low complication rates reported in patients treated with malignant liver tumors, as low as $2.4 \%$ in the largest series to date. ${ }^{4}$

A total of 33 tumor nodules were treated in 18 patients, of whom 3 patients underwent a second RFA procedure for residual disease. Data resulting after retreatment with RFA in these 3 patients were excluded from data analysis, and the day of RFA reapplication was considered the last point of follow-up. The characteristics of treated patients and the main reasons for consideration of RFA as an alternative to surgical resection are listed in Table 1.

\section{RFA Technique}

The RFA procedure was performed by two thoracic surgeons in the operating room with the patient under general anesthesia. The lesion was approached by either minithoracotomy $(5 / 18,27 \%)$ or the percutaneous route guided by computed tomography (CT, $13 / 18,72 \%)$. In the CT-guided procedures we used the services of a CT technician and used an operating room equipped with a CT scanner. After confirming successful central placement of a finder needle during CT imaging, the LeVeen needle electrode (RadioTherapeutics Corporation, Sunnyvale, Calif) size $(2-4 \mathrm{~cm})$ was chosen according to the diameter of the target lesion. The needle electrode has a diameter of 14 gauge with a $12-$ to $15-\mathrm{cm}$ shaft length and is introduced under CT guidance into the center of the lesion, inside of which the multiple tines are deployed to maximize the treatment area (Figure 1). Several applications in different locations within the lesion may be required for larger masses, with the therapy beginning at the most distal area and progressing proximally. For RFA treatments by thoracotomy, the lesion is 


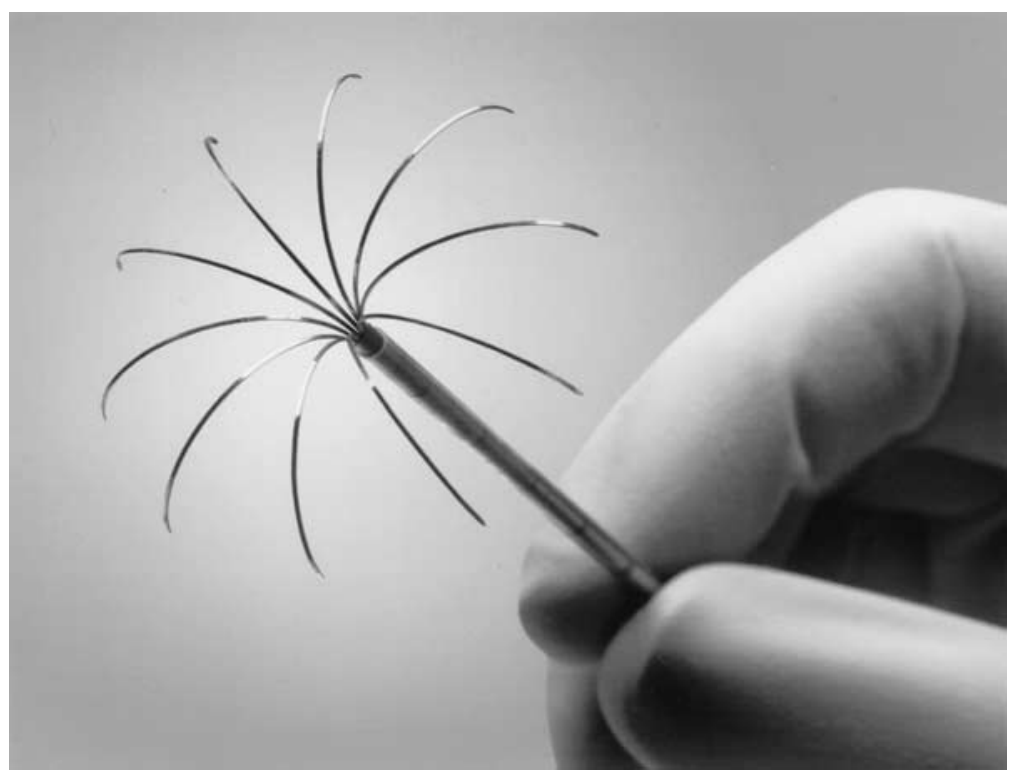

Figure 1. RFA LeVeen needle electrode with deployed multi-tine array.

TABLE 2. RFA response criteria according to radiographic appearance of the treated lesion

\begin{tabular}{|c|c|c|c|}
\hline Response & CT mass size (RECIST) & CT mass quality & PET* $^{*}$ \\
\hline $\begin{array}{l}\text { Complete ( } 2 \text { of } \\
\text { the criteria) }\end{array}$ & $\begin{array}{l}\text { Lesion disappearance } \\
\text { (scar) or }<25 \% \text { of } \\
\text { original size }\end{array}$ & $\begin{array}{l}\text { Cyst cavity formation, } \\
\text { low density }\end{array}$ & SUV $<2.5$ \\
\hline $\begin{array}{l}\text { Partial (1 of the } \\
\text { criteria) }\end{array}$ & $\begin{array}{l}>30 \% \text { decrease in sum LD } \\
\text { of target lesionst }\end{array}$ & $\begin{array}{l}\text { Mass central necrosis } \\
\text { or central cavity } \\
\text { with liquid density }\end{array}$ & $\begin{array}{l}\text { Decreased SUV or } \\
\text { area of FDG } \\
\text { uptake }\end{array}$ \\
\hline $\begin{array}{l}\text { Stable lesion (1 } \\
\text { of the criteria) }\end{array}$ & $\begin{array}{l}<30 \% \text { decrease in sum LD } \\
\text { of target lesionst }\end{array}$ & $\begin{array}{l}\text { Mass solid } \\
\text { appearance, no } \\
\text { central necrosis or } \\
\text { cavity }\end{array}$ & $\begin{array}{l}\text { Unchanged SUV or } \\
\text { area of FDG } \\
\text { uptake }\end{array}$ \\
\hline $\begin{array}{l}\text { Progression ( } 2 \text { of } \\
\text { the criteria) }\end{array}$ & $\begin{array}{l}\text { Increase }>20 \% \text { in sum LD } \\
\text { of target lesionst }\end{array}$ & $\begin{array}{l}\text { Solid mass, invasion } \\
\text { adjacent structures }\end{array}$ & $\begin{array}{l}\text { Higher SUV or larger } \\
\text { area of FDG } \\
\text { uptake }\end{array}$ \\
\hline
\end{tabular}

Modified from the RECIST criteria. ${ }^{12,13}$ SUV, Standard uptake value; sum $L D$, sum of largest diameter of all target lesions; 18-FDG, 18-fluorodeoxyglucose. *PET scan was used selectively in lesions with unclear response by CT imaging.

†Tumors treated with RFA.

stabilized with the surgeon's hand, and the needle electrode is introduced guided by palpation and direct visualization.

\section{Study End Points and Statistical Analysis}

The objectives of this study were to determine early outcomes and feasibility of RFA for malignant pulmonary tumors in patients not considered candidates for surgery and to evaluate its effect on radiographically determined tumor control. Specific end points were description and frequency of complications, radiographic evidence of tumor response after RFA treatment, and overall survival.

Results from liver RFA suggest that larger tumors do not meet with as good success rates as smaller lesions. We therefore separately analyzed results for tumors smaller than $5 \mathrm{~cm}$ and those larger than $5 \mathrm{~cm}$, for the latter of which more than one deployment of the RFA probe was always required. Patients underwent a chest CT scan for preoperative evaluation and a repeated scan after the RFA procedure before discharge from the hospital. Patient follow-up was carried out at 1 month and then at 3-month intervals with chest CT imaging. Additional imaging with positron-emission tomography (PET) was used selectively for suspected lesions according to CT scan. Clinical response was evaluated by a composite radiographic score comprising of tumor mass, tumor quality, and, when indicated, PET results. Changes in tumor mass were measured with the Response Evaluation Criteria in Solid Tumors (RECIST) protocol, which is based on objective measurements of lesion size before and after treatment. ${ }^{12,13}$ Because RFA ablation may cause accumulation of fluid and scar formation during the 

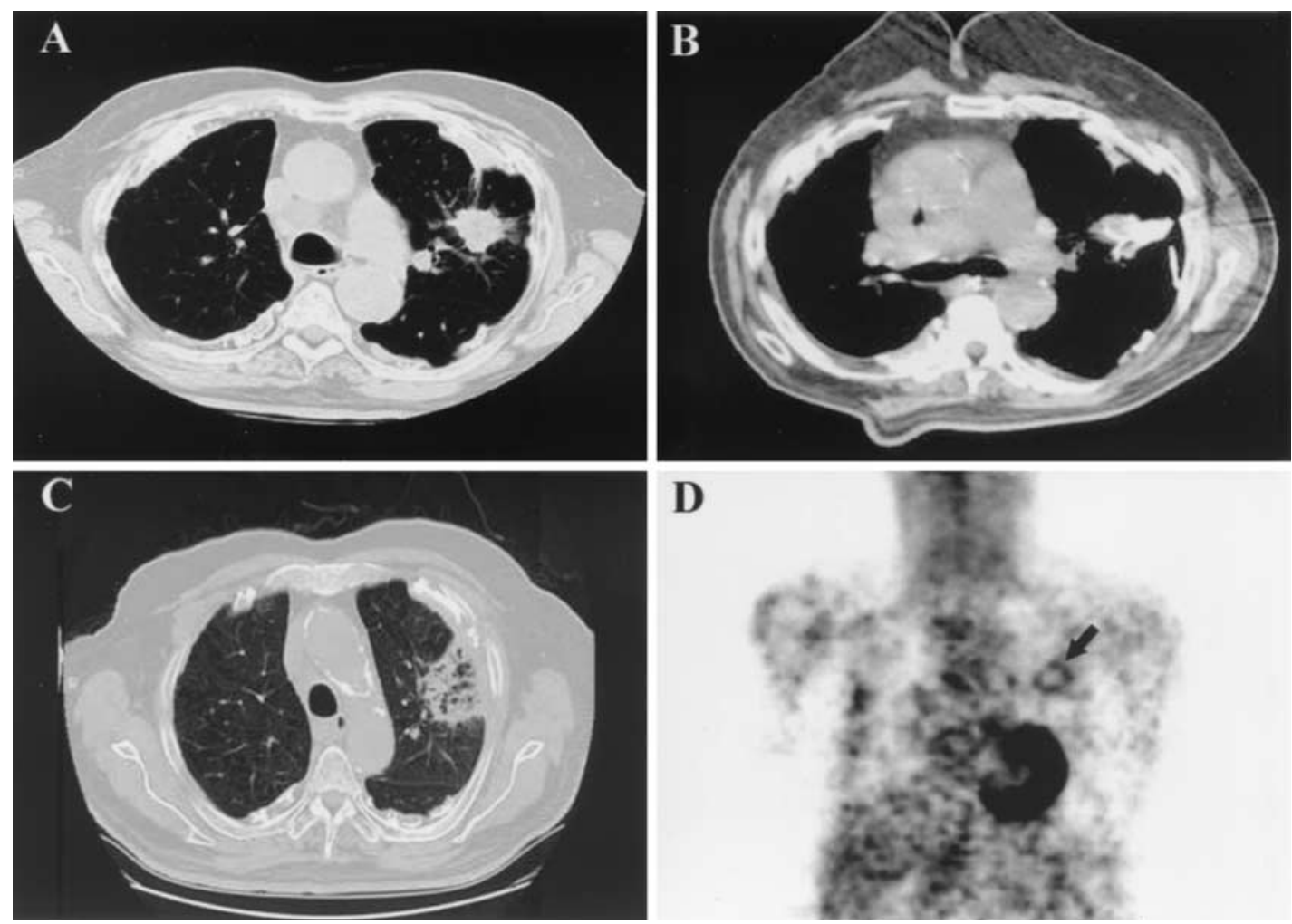

Figure 2. A 56-year-old patient with stage 1b NSCLC and severe cardiac disease treated with RFA. A, Pre-RFA chest CT scan demonstrating left upper lobe speculated 3.3-cm mass. B, Intraoperative image of RFA needle electrode impaling the tumor via a percutaneous approach. C, CT scan 5 months after RFA. Note the central hypo-attenuation and decreased density of the lesion. D, PET scan 5 months after RFA demonstrates left upper lobe lesion (arrow). Note the central photopenia and peripheral rim of 18-fluorodeoxyglucose uptake with a standardized uptake value of 1.5 (preoperative standardized uptake value 7.5 ).

healing process, the effects on lesion size sometimes are minimal. Instead, changes in the quality of the ablated tissue can be noted in lesions successfully ablated with RFA. To account for this, we modified the RECIST lesion response criteria to include a subjective evaluation of radiographic lesion characteristics on the basis of central cavity formation or fluid accumulation (Table 2). In addition, patients with lesions that were suspected of tumor persistence after RFA or that showed poor response were evaluated with 18-fluorodeoxyglucose PET scans, and the results were considered in the assessment of lesion response (Figure 2).

Descriptive statistics for the cohort were generated with SPSS statistical software (SPSS Inc, Chicago, Ill). The nonparametric Mann-Whitney test was used for analysis of ordinal variables, and the $\chi^{2}$ test was used for dichotomous variables.

\section{Results}

A total of 33 lung tumors in 18 patients were treated with RFA (Table 3). There were 12 male and 6 female patients, with a mean age of 60 years (range 27-95 years). RFA was by either minithoracotomy $(\mathrm{n}=5)$ or percutaneous CTguided approach $(\mathrm{n}=13)$. The percutaneous approach became our preferred option whenever feasible because of the advantage of avoiding a thoracotomy. The 18 patients treated had either primary NSCLC $(n=5)$ or pulmonary metastases from an extrathoracic malignancy $(\mathrm{n}=13)$. Patients with pulmonary metastases had a median of 3 lesions (range 1-10) present at the time of RFA treatment, and 5 of $13(38 \%)$ had bilateral disease. The origins of the primary tumors in patients with pulmonary metastases are described in Table 3. Five patients had primary NSCLC, 2 of whom had recurrence of disease (M1) after previous thoracotomy and resection (1 bronchoalveolar and 1 squamous cell carcinoma). The stage distribution of patients with NSCLC was as follows: stage Ia, 1; stage Ib, 2; and stage IV, 2. The mean size of the largest treated lesions was $5.3 \mathrm{~cm}$ (range 2-16.1 cm). Median length of stay for patients treated with RFA by the percutaneous approach was 2.5 days (range 1-5 days), versus 5 days (range 2-7 days) in the group treated by minithoracotomy or with combination of resection and RFA ( $P=.046$ by Mann-Whitney test).

Chest tubes were placed in all open procedures and in 7 of 13 percutaneous treatments for procedure-related pneu- 


\section{TABLE 3. Tumor characteristics}

\begin{tabular}{|c|c|c|}
\hline & No. & $\%$ \\
\hline \multicolumn{3}{|l|}{ NSCLC } \\
\hline \multicolumn{3}{|l|}{ Histologic type } \\
\hline Bronchoalveolar & 1 & 20 \\
\hline Adenocarcinoma & 1 & 20 \\
\hline Squamous cell carcinoma & 1 & 20 \\
\hline Undetermined & 2 & 40 \\
\hline \multicolumn{3}{|l|}{ Stage } \\
\hline la & 1 & 20 \\
\hline $\mathrm{lb}$ & 2 & 40 \\
\hline IV & 2 & 40 \\
\hline \multicolumn{3}{|l|}{ Size of treated lesion $(\mathrm{cm})$} \\
\hline $2-3$ & 3 & 60 \\
\hline$\geq 1-4$ & 2 & 40 \\
\hline \multicolumn{3}{|l|}{ Metastatic disease } \\
\hline \multicolumn{3}{|l|}{ Origin } \\
\hline Sarcoma & 5 & 27.8 \\
\hline Colon & 2 & 11 \\
\hline Melanoma & 1 & 5.6 \\
\hline Head and neck & 2 & 11 \\
\hline Genital & 2 & 11 \\
\hline Renal & 1 & 5.6 \\
\hline No. of metastases (median and range) & \multicolumn{2}{|c|}{$3(1-10)$} \\
\hline \multicolumn{3}{|l|}{ Size of largest lesion $(\mathrm{cm})$} \\
\hline $2-4$ & 5 & 38.5 \\
\hline $4.1-6$ & 3 & 23.1 \\
\hline $6.1-10$ & 3 & 23.1 \\
\hline$\geq 10.1$ & 2 & 15.4 \\
\hline \multicolumn{3}{|l|}{ Bilateral disease } \\
\hline Yes & 5 & 38.5 \\
\hline No & 8 & 61.5 \\
\hline
\end{tabular}

mothoraces. This complication was treated with placement of pleural pigtail catheters during CT-guided RFA at the time of the procedure to allow lung re-expansion and to stabilize the tumor location. Median durations of chest tube drainage were 3 days (range 1-6 days) for the open thoracotomy approach and 1.5 days (range 0-12 days) for the CT-guided approach $(P>.2$ by Mann-Whitney test). Other complications after lung RFA are described in Table 4. Three patients underwent a second RFA procedure to treat further metastatic disease, 1 of whom had new metastatic lesions in the chest not present at the time of initial RFA. Of these retreated patients, 1 died of massive hemoptysis 21 days after open RFA of a central nodule. This patient had also received brachytherapy 4 days before this episode of hemoptysis. After this complication, centrally located tumors were excluded from treatment with RFA.

Response rates to RFA according to our response criteria for all patients with lung tumors were as follows: complete or partial radiographically evident response in 10 of 18 patients (55\%), stable disease in 6 of 18 patients (33\%), and tumor progression in 3 of 18 patients (17\%; Table 5). The response rates seemed to be better for treated lesions smaller than $5 \mathrm{~cm}(8 / 12,66.6 \%$ response) than for those larger than
TABLE 4. Complications after RFA

\begin{tabular}{lcc}
\hline Complication & No. & $\%$ \\
\hline Pleural effusion & 9 & 50 \\
Thoracocentesis & 2 & 11 \\
Pneumothorax (CT-guided group) & 7 & 53.8 \\
Delayed pneumothorax & 1 & 5 \\
Pneumonitis or pneumonia & 4 & 22 \\
Transient acute respiratory failure & 1 & 5 \\
Massive hemoptysis & 1 & 5
\end{tabular}

$5 \mathrm{~cm}\left(2 / 6,33.3 \%\right.$ response) $\left(P=.087\right.$ by $\chi^{2}$ test $)$. None of the patients for whom a response was achieved had evidence of tumor progression at the treated site; however, 5 of 9 patients with no response after RFA (55.5\%) later showed radiographic evidence suggestive of nodule recurrence or progression $\left(P=.0085\right.$ by $\chi^{2}$ test). Of the 13 patients with pulmonary metastasis, 7 (53.8\%) had new lesions develop in the chest and $4(30.8 \%)$ had new extrathoracic metastases develop.

At a median follow-up of 6 months (range 1-10 months), 4 of the 5 patients with NSCLC are alive; the other patient died at the age of 95 years without evidence of disease progression. Of the 4 patients with NSCLC who are alive at last follow up, 3 patients have no evidence of disease. In the group with pulmonary metastases, 7 of $13(54 \%)$ are alive at a median follow-up of 4 months (range 1-13 months). Among the 6 patients with fewer than three metastatic lesions and with a maximal tumor diameter of $5 \mathrm{~cm}, 5$ are alive at a median follow-up of 7 months (Table 6).

\section{Discussion}

The mainstay of treatment of early stage NSCLC and of limited pulmonary metastases is standard surgical resection, which provides better long-term survival than does nonoperative therapy. ${ }^{3,14}$ For patients who are medically unfit for standard surgical therapy or could not tolerate complete resection, the alternative treatment options are limited mainly to chemotherapy and external beam radiation.

For patients with early stage NSCLC, available alternatives to standard lobectomy or pneumonectomy are limited resections or definitive high-dose radiotherapy. Limited resection, however, should continue to be viewed as a compromise operation for primary lung cancer because it carries increased rates of locoregional recurrence. ${ }^{15}$ In addition, this approach requires thoracoscopy or thoracotomy, which may not be tolerated by patients with severe comorbidities or may not be acceptable to patients who refuse surgical intervention. As a second alternative, definitive radiation therapy can be used in selected cases of medically inoperable early stage (I and II) NSCLC. In a meta-analysis comprising 26 nonrandomized studies totaling more than 2000 patients, overall 5-year survival ranged from $0 \%$ to 
TABLE 5. Determination of final radiographically evident response with each response criterion

\begin{tabular}{|c|c|c|c|c|c|c|}
\hline Patient & Tumor type & $\begin{array}{l}\text { Nodules treated } \\
\text { with RFA (No.) }\end{array}$ & RECIST & $\begin{array}{c}\text { CT lesion } \\
\text { characteristics }\end{array}$ & PET & $\begin{array}{c}\text { Final } \\
\text { response }\end{array}$ \\
\hline 1 & Metastatic, sarcoma & 2 & PD & PR & NA & PR \\
\hline 2 & Metastatic, sarcoma & 1 & PD & PD & NA & PD \\
\hline 3 & $\begin{array}{l}\text { Metastatic, head and } \\
\text { neck }\end{array}$ & 2 & SD & PR & NA & PR \\
\hline 4 & Metastatic, colon & 1 & SD & PR & CR & CR \\
\hline 5 & Metastatic, sarcoma & 1 & SD & SD & NA & SD \\
\hline 6 & Metastatic, renal & 2 & SD & PR & NA & PR \\
\hline 7 & Metastatic, sarcoma & 2 & SD & PD & NA & PD \\
\hline 8 & Metastatic, cervix & 1 & PR & PR & NA & PR \\
\hline 9 & Bronchoalveolar & 2 & SD & PR & SD & SD \\
\hline 10 & NSCLC & 1 & SD & SD & NA & SD \\
\hline 11 & Metastatic, sarcoma & 2 & SD & PD & NA & PD \\
\hline 12 & NSCLC & 1 & SD & PR & CR & PR \\
\hline 13 & Metastatic, testicular & 1 & SD & PR & CR & PR \\
\hline 14 & $\begin{array}{l}\text { Metastatic, head and } \\
\text { neck }\end{array}$ & 3 & PD & PR & SD & SD \\
\hline 15 & $\begin{array}{l}\text { Metastatic, } \\
\text { melanoma }\end{array}$ & 1 & PD & SD & NA & SD \\
\hline 16 & $\begin{array}{l}\text { Metastatic, head and } \\
\text { neck }\end{array}$ & 2 & PD & PR & PR & PR \\
\hline 17 & Metastatic, colon & 2 & SD & SD & NA & SD \\
\hline 18 & NSCLC & 1 & SD & PR & NA & PR \\
\hline
\end{tabular}

$P D$, Progressive disease; $P R$, partial response; $N A$, not available; $S D$, stable disease; $C R$, complete response.

$42 \%$, with complete response rates between $33 \%$ and $61 \%$. However, reported local failure rates varied between $6 \%$ and $70 \% .{ }^{16}$ Similar results were reported in other retrospective studies, each comprising more than 140 patients with stage I medically inoperable NSCLC, with overall 5-year survivals of $13 \%$ to $22 \%$, a cause-specific 5-year survival of $32 \%$, and local failure rates of $42 \%$ to $44 \% .{ }^{17,18}$

Patients with isolated pulmonary metastases from extrathoracic malignancies who cannot undergo complete resection have poor survival. In a study of 5206 cases of lung metastasectomy, the International Registry of Lung Metastases reported an actuarial 5-year survival of 36\%, which compared favorably with a 5-year survival of $13 \%$ among patients who underwent incomplete resection. ${ }^{3}$ Patients who are not operative candidates for medical reasons have limited treatment options, because many secondary lung tumors are not radiosensitive or comprise a large radiation field. Furthermore, many of these patients have already had failure of aggressive chemotherapy regimens by the time they are seen for surgical consideration. There are no large series of chemotherapy for isolated pulmonary metastases. Response rates for metastatic colon carcinoma of $9 \%$ to $45 \%$ have been reported, but with a mean progression free survival of 2 to 4 months. ${ }^{19,20}$

The major advantage of RFA therapy is that it allows ablation of tumors without major damage to surrounding normal parenchyma. ${ }^{6,721}$ In addition, the technique can be performed percutaneously, thus avoiding a thoracotomy for patients with severe comorbidities or those who refuse open resection. These features make this technique a potential tool for local control for certain patients who cannot undergo standard surgical therapy. However, the efficacy of RFA for the treatment of lung tumors is still unclear, and a larger phase II study is necessary to determine its ablation potential and its role in local tumor control relative to standard radiation therapy.

RFA is now increasingly used for the treatment of hepatic malignant tumors. Reported results vary according to the series, and recurrence at treated sites is more likely after ablation of larger lesions. 5 Probably the best results are those of 123 patients reported by Curley and associates. ${ }^{4}$ Initial successful ablation was seen in $100 \%$ of patients, with local recurrence in $1.8 \%$ at a median follow-up of 15 months. Another series reported successful ablation of only $69 \%$ of 72 liver tumors. ${ }^{22}$ Our own data indicate that lung RFA may not be as effective. This may be due in part to a learning curve, however, particularly with percutaneous techniques, and to patient selection, which did not exclude patients with larger tumors. In addition, a more solid texture of the tumor may allow more precise application of thermal energy than could be achieved in the lung.

In this study we reviewed our initial experience with RFA for the treatment of pulmonary malignancies in patients not considered surgical candidates. Because of the limited clinical experience in the treatment of lung tumors with RFA, we considered patients for this procedure if 
resection was not possible because of patient comorbidity, prohibitive pulmonary reserve, or patient refusal. Three patients had failure of radiation or chemotherapy for extensive disease localized to the chest for which RFA was attempted as an adjunct to achieve local tumor control for palliation. We have demonstrated that the procedure can be performed either by thoracotomy or percutaneously with CT guidance. Complication rates were acceptable in our initial experience and consisted of pneumothoraces that resolved in an average of 1 day in the patients treated percutaneously. Pleural effusions were common but required drainage in only 2 patients. We had 1 death in our experience, that of a patient with massive hemoptysis 19 days after open RFA of a central nodule. This patient had also received brachytherapy 4 days before his death. Although it is unclear which therapy caused this complication, caution should be used when applying RFA to central nodules near the hilum. Two patients were readmitted with pneumonitis, and 1 patient also had transient acute renal failure develop.

One of the difficulties with RFA therapy is evaluating the response to treatment radiographically. In the experience with liver tumors, radiographic assessment has been used successfully to determine the effectiveness of RFA. Mainly with the use of CT scans, changes in the quality of the ablated lesion can be appreciated, with or without a decrease in the volume or size of the lesion. Magnetic resonance imaging has also been described for assessment of response after RFA of liver lesions, because it can provide information about the density and composition of the tumor, but we have not used this modality for follow-up. Our approach to assessing the tumor response was based on changes in the size and quality of the ablated lesion on CT scans. The addition of PET scans after RFA seems to define the effectiveness of RFA treatment more clearly than do CT scans alone, and PET scan may be useful to confirm the presence of persistent disease in lesions that show growth or solid appearance of the lesion on CT.

Of the 13 patients with pulmonary metastasis, 9 patients (69\%) had new metastases develop after RFA treatment, and 5 of these 9 patients (56\%) had new metastases develop in the chest. In addition, in 3 of the 13 cases there were radiographic changes suggestive of persistence or recurrence of the treated nodule. This could be explained in part by the large size of the metastatic lesions treated, with a mean size of $6.1 \mathrm{~cm}$, a size for which RFA has shown limited effectiveness in the treatment of liver tumors. Of the 13 patients with pulmonary metastases treated with RFA, 6 (46.1\%) died during the follow-up period, again suggestive of the extensive disease present in some of these patients.

Our initial experience suggests that RFA is technically feasible with acceptable complication rates and could potentially provide local control for selected patients with malignant pulmonary tumors. Better selection criteria for
TABLE 6. Response to RFA and survival

\begin{tabular}{|c|c|c|c|c|}
\hline & $\begin{array}{l}\text { NSCLC } \\
(n=5)\end{array}$ & $\begin{array}{c}\text { Metastatic } \\
(\mathrm{n}=13)\end{array}$ & $\begin{array}{c}\text { Size }>5 \mathrm{~cm} \\
(\mathrm{n}=6)\end{array}$ & $\begin{array}{c}\text { Size }<5 \mathrm{~cm} \\
(\mathrm{n}=12)\end{array}$ \\
\hline Lesions* (No.) & 5 & 23 & 10 & 18 \\
\hline \multicolumn{5}{|c|}{ Complete response } \\
\hline No. & 0 & 1 & 0 & 1 \\
\hline$\%$ & 0 & 7.7 & 0 & 8.3 \\
\hline \multicolumn{5}{|l|}{ Partial response } \\
\hline No. & 2 & 5 & 2 & 7 \\
\hline$\%$ & 40 & 38.5 & 33.3 & 58.3 \\
\hline \multicolumn{5}{|l|}{ Stable disease } \\
\hline No. & 3 & 4 & 2 & 3 \\
\hline$\%$ & 60 & 30.8 & 33.3 & 25 \\
\hline \multicolumn{5}{|c|}{ Progressive disease } \\
\hline No. & 0 & 3 & 2 & 1 \\
\hline$\%$ & 0 & 23.1 & 33.3 & 8.3 \\
\hline \multicolumn{5}{|c|}{ Alive with no evidence of disease } \\
\hline No. & 3 & 2 & 1 & 5 \\
\hline$\%$ & 60 & 15.4 & 17 & 41.7 \\
\hline \multicolumn{5}{|c|}{ Alive with disease } \\
\hline No. & 1 & 5 & 1 & 3 \\
\hline$\%$ & 20 & 38.4 & 17 & 25 \\
\hline \multicolumn{5}{|l|}{ Died } \\
\hline No. & 1 & 6 & 4 & 4 \\
\hline$\%$ & 20 & 46.2 & 66 & 33.3 \\
\hline
\end{tabular}

*Data from 3 patients who underwent second RFA treatment (5 tumors) were excluded from response and survival analysis.

this therapy as part of a prospective clinical trial, together with more standardized methods for radiographic followup, are needed to demonstrate the effectiveness of RFA for lung tumor ablation and its impact on patient survival.

\section{Conclusions}

RFA seems to be technically feasible for the treatment of selected pulmonary tumors with acceptable complication rates. Nine of 18 patients in whom a complete or partial response was achieved were less likely to have a subsequent recurrence in the RFA-treated lesions, but a significant number of patients had new intrathoracic and extrathoracic metastases develop after RFA. A trend toward a better radiographically determined response was observed in patients with lesions smaller than $5 \mathrm{~cm}$. Additional trials with established patient selection criteria are needed to determine the safety and efficacy of RFA and its impact on survival relative to standard therapy. Thoracic surgeons must continue to evaluate minimally invasive techniques such as RFA for local tumor control in patients thought not to be surgical candidates.

\section{References}

1. Boring CC, Squires TS, Tong T, Montgomery S. Cancer statistics, 1994. CA Cancer J Clin. 1994;44:7-26.

2. Greenlee RT, Murray T, Bolden S, Wingo PA. Cancer statistics, 2000. CA Cancer J Clin. 2000;50:7-33. 
3. Pastorino U, Buyse M, Friedel G, Ginsberg RJ, Girard P, Goldstraw P, et al. Long-term results of lung metastasectomy: prognostic analyses based on 5206 cases. The International Registry of Lung Metastases. J Thorac Cardiovasc Surg. 1997;113:37-49.

4. Curley SA, Izzo F, Delrio P, Ellis LM, Granchi J, Vallone P, et al. Radiofrequency ablation of unresectable primary and metastatic hepatic malignancies: results in 123 patients. Ann Surg. 1999;230:1-8.

5. Bilchik AJ, Wood TF, Allegra DP. Radiofrequency ablation of unresectable hepatic malignancies: lessons learned. Oncologist. 2001;6:2433.

6. Putnam JB Jr, Thomsen SL, Siegenthale M. Therapeutic implications of heat-induced lung injury. Crit Rev Optical Sci Technol. 2000;75: 139-60.

7. Goldberg SN, Gazelle GS, Compton CC, Mueller PR, McLoud TC. Radio-frequency tissue ablation of VX2 tumor nodules in the rabbit lung. Acad Radiol. 1996;3:929-35.

8. Dupuy DE, Zagoria RJ, Akerley W, Mayo-Smith WW, Kavanagh PV, Safran H. Percutaneous radiofrequency ablation of malignancies in the lung. AJR Am J Roentgenol. 2000;174:57-9.

9. Dupuy DE, Goldberg SN. Image-guided radiofrequency tumor ablation: challenges and opportunities-part II. J Vasc Interv Radiol. 2001;12:1135-48.

10. Sewell PE, Vance RB, Wang YD. Assessing radiofrequency ablation of non-small cell lung cancer with positron emission tomography (PET) [abstract]. Radiology. 2000;217(Suppl):334.

11. Kang S, Luo R, Liao W, Wang C, Luo Y. Effect of radiofrequency ablation on lung cancer [abstract 1342]. Presented at the 37th Annual Meeting of the American Society of Clinical Oncology; 2001 May 15; San Francisco.

12. Padhani AR, Ollivier L. The RECIST (Response Evaluation Criteria in Solid Tumors) criteria: implications for diagnostic radiologists. $\mathrm{Br} \mathrm{J}$ Radiol. 2001;74:983-6.

13. Tsuchida Y, Therasse P. Response evaluation criteria in solid tumors (RECIST): new guidelines. Med Pediatr Oncol. 2001;37:1-3.

14. Rusch VW. Pulmonary metastasectomy. Current indications. Chest. 1995;107(6 Suppl):322S-31S.

15. Ginsberg RJ, Rubinstein LV. Randomized trial of lobectomy versus limited resection for T1 N0 non-small cell lung cancer. Lung Cancer Study Group. Ann Thorac Surg. 1995;60:615-22.

16. Rowell NP, Williams CJ. Radical radiotherapy for stage I/II non-small cell lung cancer in patients not sufficiently fit for or declining surgery (medically inoperable): a systematic review. Thorax. 2001;56:628-38.

17. Sibley GS, Jamieson TA, Marks LB, Anscher MS, Prosnitz LR. Radiotherapy alone for medically inoperable stage I non-small-cell lung cancer: the Duke experience. Int J Radiat Oncol Biol Phys. 1998;40:149-54.

18. Morita K, Fuwa N, Suzuki Y, Nishio M, Sakai K, Tamaki Y, et al. Radical radiotherapy for medically inoperable non-small cell lung cancer in clinical stage I: a retrospective analysis of 149 patients. Radiother Oncol. 1997;42:31-6.

19. Zori CA, Blajman C, Richardet E, Bella S, Vilanova M, Coppola F, et al. A randomised phase II study of oxaliplatin alone versus oxaliplatin combined with 5-fluorouracil and folinic acid (Mayo Clinic regimen) in previously untreated metastatic colorectal cancer patients. Eur $J$ Cancer. 2001;37:1006-13.

20. Gil-Delgado MA, Guinet F, Castaing D, Adam R, Coeffic D, Durrani AK, et al. Prospective phase II trial of iriontecan, 5-fluorouracil, and leucovorin in combination as salvage therapy for advanced colorectal cancer. Am J Clin Oncol. 2001;24:101-5.

21. Miao Y, Ni Y, Bosmans H, Yu J, Vaninbroukx J, Dymarkowski S, et al. Radiofrequency ablation for eradication of pulmonary tumor in rabbits. J Surg Res. 2001;99:265-71.

22. Rhim H, Dodd GD 3rd. Radiofrequency thermal ablation of liver tumors. J Clin Ultrasound. 1999;27:221-9.

\section{Discussion}

Dr Richard Whyte (Palo Alto, Calif). I congratulate Herrera and colleagues for continuing to push the envelope in both the treatment of the thoracic malignant tumors and the role of the surgeon in treating these ailments. This series presents the results of RFA of 33 lung tumors in 18 patients. The sizes ranged from 1 to $16 \mathrm{~cm}$, and the results showed that radiographic evidence of improvement was common in the small lesions but less likely in the large lesions. The procedure was reasonably safe, although there was 1 death, and serious complications were uncommon. I appreciate the reference to our article at The American Association for Thoracic Surgery meeting, where we presented the results of the combined experience of Stanford, M.D. Anderson, and Johns Hopkins. We also found that small lesions were more reliably ablated than larger ones. We also did all our procedures in an open fashion and noticed a clear learning curve in positioning the electrode.

I have three questions for Dr Herrera. First, do you think that these arrays are better placed under CT guidance than through an open thoracotomy? If so, should we as thoracic surgeons take steps to learn CT-guided techniques?

Dr Herrera. Our experience suggests that it was more beneficial for the patient to avoid a thoracotomy if the same result could be achieved. In our experience the assistance of radiographic imaging did help to place the electrode in the center of the lesion. However, there are cases where the combination of resection with ablation of a lesion in a separate lobe to avoid a second or third resection would make a thoracotomy approach more beneficial. It is too early to say. I think that it is going to come down in part to surgeon's preference.

Dr Whyte. It is my understanding that the University of Pittsburgh is unique in the sense that you have CT available to you in the operating room, which most institutions do not have.

My second question relates to your criteria for evaluating the response. Your criteria involve three components: CT-measured size, CT-assessed quality, and PET scan results. I found it interesting that size and quality results were only concordant in 5 of 18 patients. How did you account for these discrepancies and come up with a "final response," and how did this final response rate translate into cure, which is the ultimate test of efficacy?

Dr Herrera. That is a good question. Obviously there are no data available for how to evaluate these responses, so we tried to generate criteria that were reproducible amongst our assessment. In terms of size, you will notice that after therapy with RFA you may see early on an increase in size with surrounding parenchymal hemorrhage or pneumonitis. This tends to resolve, however, and the size starts to decrease. Ours was a short follow-up so it is hard to say what the outcome in terms of size is going to be, but we suspect that responders are going to have a decrease or at least no increase in lesion size. The discrepancies are true, but we put more weight on the presence of cavity formation and PET also was useful in complementing this assessment. I agree that the patient population and the size were heterogeneous, and the assessment of size in such a diverse group is a little bit more challenging.

Dr Whyte. Finally, what do you and your colleagues think might be the ultimate role for RFA in the treatment of both primary and metastatic lung cancers?

Dr Herrera. It is still too early to tell. I think that there may be a role, and thoracic surgeons should consider this as a potential tool for treatment of these challenging patients who cannot undergo resection. These procedures are being done by radiologists throughout the country, and with the advent of new CT screening modalities I think the radiologists may have access to a lot of these 
lesions before thoracic surgeons do. So I think it is critical to select patients who would not benefit from or cannot undergo a resection, which I think is the ultimate therapy. I do not think that RFA will substitute for current standard of surgical resection.

Dr John Mitchell (Denver, Colo). I have a question to follow up on what Dr Whyte asked. It concerns the use of PET scanning to evaluate response to therapy. I wonder whether the inflammatory response induced by your therapy might confound the PET results.

Dr Herrera. That is a good question. Unfortunately, only 6 of the 18 patients had PET scans performed after RFA, and these were done because of questionable responses in terms of CT findings. I think that PET scan becomes a very useful modality in combination with CT to provide a better assessment of response. It is true that the inflammatory process that has been shown pathologically in animal studies can have uptake of 18-fluorodeoxyglucose and yield a false result; however, we see that this rim surrounding the tumor with central photopenia is characteristic of a response, and the standard uptake values are much lower than in the preoperative PET scan, which most patients underwent to exclude extrathoracic disease.

Dr John R. Benfield (Los Angeles, Calif). In the practical world I foresee this becoming a radiologic procedure, or at least not a primary surgical procedure, in most centers. If that happens, there will be a group of patients who will have complications from the procedure- bronchopleural fistulas, empyemas, and so forthand will come to us as thoracic surgeons to manage. If that happens, it is going to be hard for us to have an overview regarding the efficacy and safety of the procedure.

I have two questions. First, at present is the procedure being done in a small enough number of places that one could identify those places and try to develop a prospective study?

Dr Herrera. Yes. As I understand, there are few published data on this, but a few abstracts have been presented from two or three centers. There is a radiologist at the University of Mississippi who has performed more than 100 of these and claims a very good success rate, better than $90 \%$. These are unpublished data. There is a Japanese group that has done more than 100 as well, and again these are unpublished data, but they claim a good response as assessed by PET scans. As we all know, Dr Whyte at Stanford and M.D. Anderson and the University of Maryland have had some experience with this. I think that the best way to assess it is to establish critical or specific selection criteria and evaluate it that way.

Dr Benfield. I think that is correct, but beyond that it would be good, as was done in the early days of video-assisted thoracoscopic surgery, if the centers doing this would pool their data and provide a long-term follow-up. Only in this way would we know promptly and accurately the true incidence of complications.

Dr Herrera. That is a good point. I think that in addition, we are fortunate at the University of Pittsburgh to have an operating room that belongs to the neurosurgeons, where they do their stereotactic surgery. So in our case it is easier for our division of thoracic surgery to perform these procedures, but I understand that is not the case elsewhere.

Dr Matthew Blum (Chicago, Ill). I was wondering whether the "rolloff" that you noticed has been correlated with complete tumor ablation. Is the lung around the tumor relatively protected, so that you can apply energy even beyond the rolloff to ensure that you have tumor kill?

Dr Herrera. Right. Ideally you would want to ablate an area of about $1 \mathrm{~cm}$ surrounding the lesion. Rolloff or the achievement of impedance depends on the tumor size and the solid component of the lesion. It does correlate. We did not look at that in particular, but there have been animal studies that suggest that an inability to achieve rolloff suggests an incomplete response or incomplete ablation. It is something for which we would have to account for in a prospective study. 